
\title{
25 Research Soure \\ Clinical application of and nursing practices for convalescent plasma transfusion in patients with COVID-19
}

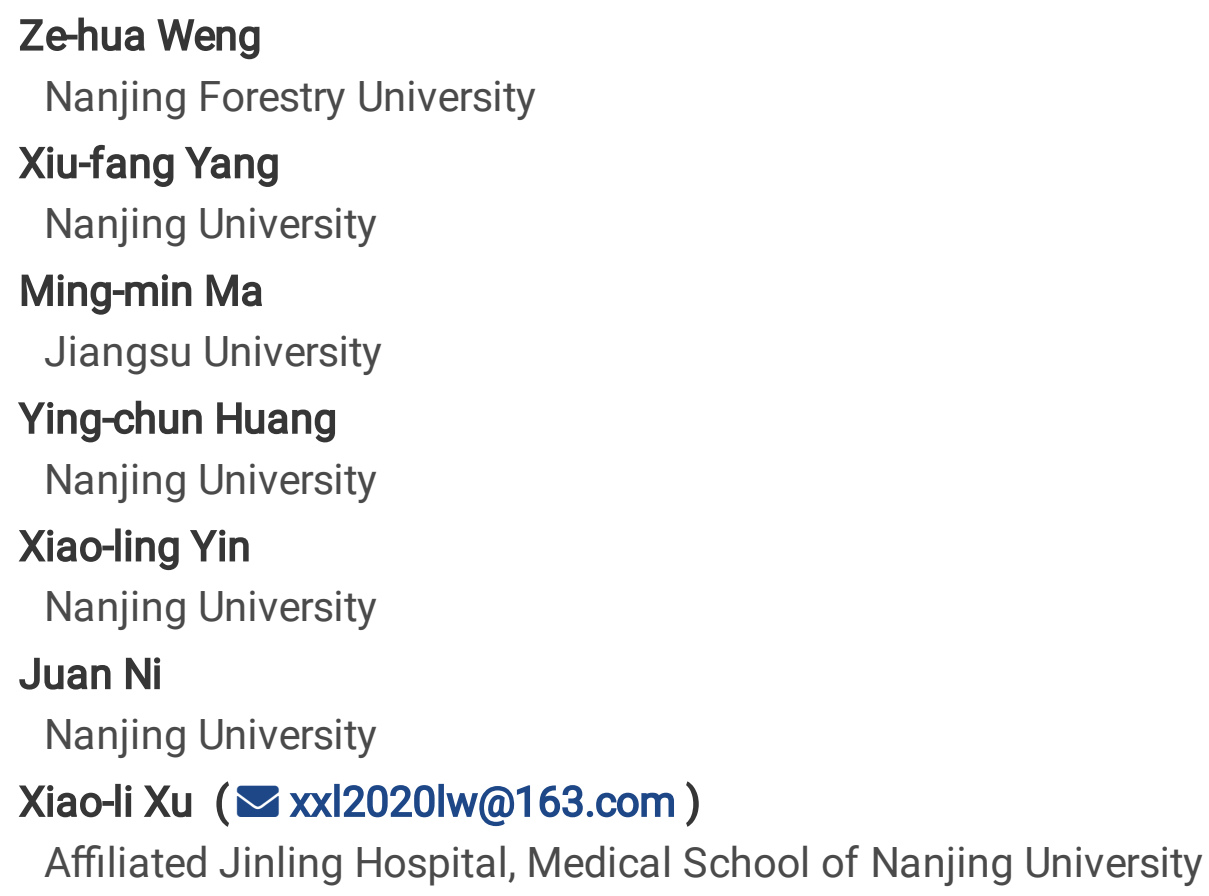

Zehua Weng

Nanjing Forestry University

Xiu-fang Yang

Nanjing University

Ming-min Ma

Jiangsu University

Ying-chun Huang

Nanjing University

Xiao-ling Yin

Nanjing University

Juan $\mathbf{N i}$

Nanjing University

Xiao-li Xu( $\nabla x x \mid 2020 l w @ 163 . c o m$ )

Affiliated Jinling Hospital, Medical School of Nanjing University

\section{Research Article}

Keywords: COVID-19, convalescent plasma transfusion, nursing

Posted Date: November 12th, 2021

DOI: https://doi.org/10.21203/rs.3.rs-1052853/v1

License: (c) (1) This work is licensed under a Creative Commons Attribution 4.0 International License. Read Full License 


\section{Abstract}

Background: This study aimed to examine the effect of convalescent plasma transfusion on patient with severe coronavirus disease ( COVID-19) and discussed the main nursing practices. Methods: We retrospectively analyzed the clinical data of 21 patients with severe COVID-19 who had received convalescent plasma transfusion therapy between March 1 and April 1, 2020. The observation indicators included leukocyte, lymphocyte, C-reactive protein (CRP), interleukin-6 (IL-6), and viral antibody levels; test results from pharyngeal swabs; nucleic acid test results; chest CT results; and respiratory symptoms. Further, we summarized the nursing practices related to plasma transfusion. Results: Neither death nor transfusion-related adverse reactions were observed in patients treated with convalescent plasma transfusion. Their antibody levels, especially lgG $(P<0.05)$, were increased to different levels, whereas the levels of inflammatory markers (CRP), white blood cells, and lymphocytes were significantly decreased ( $P$ $<0.05)$. Respiratory symptoms showed an improvement, and chest CT showed stable findings. Conclusions: Convalescent plasma transfusion is safe and feasible. It can increase antibody levels, reduce inflammatory factor levels, improve white blood cell and lymphocyte counts, and improve respiratory symptoms in patients with severe COVID-19. Thus, plasma transfusion can be used as a new, effective COVID-19 treatment method that requires cooperation from nursing.

\section{Background}

Coronavirus disease 2019 (COVID-19), caused by severe acute respiratory syndrome coronavirus 2 (SARS-CoV-2), has spread rapidly around the world since December 2019, with high transmission rate and mortality. The clinical manifestations range from no symptoms to respiratory failure [1]. Current, there are no specific effective antiviral treatments for COVID-19, limited to general supportive care, with provision of critical care. Therefore, as an unprecedented global public health crisis, safe and effective treatment is urgently needed.

Convalescent plasma treatment is the process of obtaining safe, high-titer neutralizing antibodies and infusing them into patients, which is done by collecting the plasma of patients under rehabilitation under strict preparation procedures. Convalescent blood products could be a valid option for the treatment of infectious diseases in conjunction with other drugs, or as the only therapy when a specific treatment is not available [2]. Convalescent plasma transfusion, that is, passive antibody transfusion from a previous human survivor, used to be the only known effective treatment for Ebola infection [3]. Additionally, it has been used to treat Middle East respiratory syndrome (MERS) coronavirus in 2015, SARS-CoV, H5N1 avian influenza, and H1N1 influenza [4-8]. A study of 80 patients with SARS has reported that patients who received convalescent plasma had better outcomes than did those who did not receive convalescent plasma [9]. A meta-analysis study evaluated the clinical efficacy of convalescent plasma and other treatments on severe viral acute respiratory infections and showed that the mortality rate was significantly reduced with convalescent plasma treatment [10]. Recently, convalescent plasma has also been used in patients with COVID-19, but some study identified no significant differences in clinical 
status or overall mortality between patients treated with convalescent plasma and those who received placebo [1].

In this study, we evaluated the safety and efficacy of convalescent plasma infusion in the treatment of 21 patients with COVID-19, and summarized the nursing points.

\section{Materials And Methods}

\section{Patients}

From March 1 to April 1, 2020, total 21 patients with laboratory-confirmed COVID-19 were recruited, including 12 male and 9 female patients (average age $63.67 \pm 12.82$ years). All 21 patients had fever and/or respiratory symptoms at admission. Additionally, they had imaging features of COVID-19, and 7 of them had oxygenation index of less than $300 \mathrm{mmHg}$. These patients were diagnosed and classified into three clinical types according to the New Coronavirus Pneumonia Diagnosis and Treatment Program ( $7^{\text {th }}$ edition) published by the National Health Commission of China [11], including 10 patients with common type, 8 with severe type and 3 with critical type early stage. Additionally, among these patients, 12 patients had hypertension, coronary heart disease, diabetes or other underlying diseases, and 9 patients had no underlying diseases. The inclusion criteria were as follows: 1) positive nucleic acid test or clinical expert determination of the patient with viremia; 2 ) with common, severe or critical early stage disease with rapid disease progression; 3 ) patients who were evaluated by clinical specialists for the need of convalescent plasma treatment. This study was approved by the Ethics Committee of our institution and informed consent was obtained from each patient or candidate.

\section{Intervention}

The plasma containing specific antibodies for COVID-19 were performed virus inactivation and multiple negative pathogens biological tests. The plasma infusion dose was determined by the clinical status, patient weight, etc. Accordingly, each received 1 or 2 consecutive transfusions of 100 to $500 \mathrm{~mL}$ of convalescent plasma (4-5 ml/ $\mathrm{kg}$ ). In addition to standard treatment, all patients allowed to receive general therapies including bed rest, intensive supportive treatment, close monitoring of vital signs, adequate energy intake, oxygen therapy, treating other underlying diseases, antiviral therapy (chloroquine phosphate $500 \mathrm{mg}$ orally twice daily or abidore $200 \mathrm{mg}$ orally 3 times daily (no more than 10 days)), and Chinese medicine decoction treatment.

\section{Observation index}

The average length of hospital stay, mortality rate, and incidence of adverse transfusion reactions of patients who underwent plasma transfusion were recorded. Blood samples were collected before and after plasma transfusion to measure white blood cells, lymphocytes, C-reactive protein (CRP), interleukin6 (IL-6), viral antibodies, and so on. Simultaneously, nucleic acid assay of throat swabs, chest CT scans, and respiratory tract symptom assessments were conducted. 


\section{Nursing highlights}

\section{Informed consent}

The purpose and risks of convalescent plasma transfusion were communicated with the patients and their families in detail. All patients provided consent in accordance with Informed Consent for Plasma Treatment in the Rehabilitation Period of New Coronary Pneumonia Patients. If the patient had no capacity for civil conduct or could not sign the consent form because of other circumstances, the treating physician would communicate with the family over the telephone and obtain detailed information, such as the family name, relationship, and main opinions, while recording the call.

\section{Preparation before infusion}

According to indications, we carefully screened the patients and completed preparations for blood group, blood group antibody, infectious disease, viral antibody IgM and IgG, and nucleic acid testing one day in advance. Infusion was performed according to the principle of cross-matching blood secondary compatibility.

\section{Application}

The doctor in charge of the bed filled out the "Application Form for Plasma in the Rehabilitation Period of New Coronary Pneumonia Rehabilitation Persons." Following a discussion by the expert team of the department, the paper application form was submitted to the laboratory by the team leader, and the relevant information was reported to the hospital for review.

\section{Plasma distribution}

After examination and approval by the hospital, the laboratory held the "Notice of Blood Dispensing for Plasma Therapy in Rehabilitation of New Coronary Pneumonia", applied to the blood center for the recovery period plasma in a clean ambulance, and distributed it to clinical departments in strict accordance with the relevant system of blood distribution management.

Receiving plasma in the rehabilitation period was ranked according to the following scores, with the highest cumulative score being preferred:

Pulmonary imaging showed multi-leaf lesions or lesion progression within 48 hours $>50 \%$ (1 point); increased breathing rate ( $\geq 30$ times/min), difficulty breathing, cyanosis of lips ( 1 point); $\mathrm{PaO}_{2} / \mathrm{FiO}_{2}: 200$ mmHg-300 mmHg (2 points); $\mathrm{PaO}_{2} / \mathrm{FiO}_{2}: 100$ mmHg-199 mmHg (3 points); $\mathrm{PaO}_{2} / \mathrm{FiO}_{2}<100 \mathrm{mmHg}(4$ points).

Control of the infusion process

(1) Checking the system accurately 
Before infusion, 2 medical staff members checked the patient's bed number, name, hospitalization number, blood type, blood volume, blood bag number, blood expiration date, blood appearance quality, blood transfusion device, and delivery results of the cross-matching blood test. Before transfusion, antiallergic drugs, such as dexamethasone (5-10 mg push), promethazine (25 mg intramuscular injection), and so on, were given according to doctor's orders.

(2) Speed control

During the first 15 minutes, slow infusion with no more than 20 drops/min was performed. If there was no discomfort, speed was adjusted to normal rate. The infusion process was closely observed. If an adverse reaction occurred, infusion was suspended.

(3) Infusion time and volume

Administration of the infusion was divided into 1 or 2 times. If the infusion was divided into 2 times, the interval time was $>15 \mathrm{~min}$. The number of plasma infusions was not more than 2 , and the interval between two infusion was not less than 2 days. For adults and children weighing less than $45 \mathrm{~kg}$, the total infusion dose was calculated at $4-5 \mathrm{~mL} / \mathrm{kg}$.

(4) Observation of adverse reactions

Before, during, and after plasma transfusion, any potential adverse reactions of blood transfusion were closely monitored, promptly handled, and recorded in detail.

(5) Evaluation

After treatment, the doctor's instructions for close monitoring were followed, the effectiveness of the intervention was evaluated, and the changes in the corresponding review indicators were recorded in a timely manner.

\section{Results}

\section{Improvement of respiratory symptoms by convalescent plasma transfusion}

The average length of hospital stay of the patients who received plasma transfusion was $22.05 \pm 12.45$ days. None of the patients died, and no adverse reaction occurred during the transfusion. Four of the cases (19\%) were positive for nucleic acid before plasma transfusion but turned negative after $2,3,4$, and 8 days with transfusion, respectively; The other 17 cases were negative for nucleic acid before plasma transfusion. Moreover, chest CT showed a decrease in the area of infected lesions in 17 of the cases (81\%), and reports prompted improvement or obvious improvement; The other 4 cases had higher absorption or remained stable compared with pre-transfusion (Table S1). After 2 to 5 days of transfusion, 16 cases showed obvious improvement on respiratory symptoms including cough, wheezing, chest 
discomfort and so on; the other 5 had no obvious respiratory symptoms. In addition, $\mathrm{PO}_{2} / \mathrm{FiO}_{2}$ in all patients was over 300 before discharge.

\section{Convalescent plasma transfusion-induced increase in antibody levels}

After convalescent plasma transfusion, the serum SARS-CoV-2 IgG and IgM in most patients increased to varying degrees (Figure 1). Among them, IgG showed a statistically significant change $(P<0.05)$, whereas IgM exhibited no significant difference $(P>0.1)$.

\section{Convalescent plasma transfusion-induced decrease in inflammation}

Convalescent plasma transfusion dramatically decreased the level of inflammatory factor (CRP) and improved the levels of white blood cells and lymphocytes in patients $(P<0.05)$ (Table 1 and Table S2).

\section{Abbreviations}

C-reactive protein (CRP), interleukin-6 (IL-6)

Severe acute respiratory syndrome coronavirus 2 (SARS-CoV-2)

World Health Organization (WHO)

National Institute of Allergy and Infectious Diseases (NIAID)

Middle East respiratory syndrome (MERS)

sequential organ failure assessment (SOFA)

\section{Declarations}

\section{Ethics approval and consent to participate}

This study was approved by the Ethics Committee of our institution (Ethics Approval No. HSSLL015). Early in the epidemic of coronavirus disease 2019, the Chinese government recruited a proportion of healthcare workers to support the designated hospital (Huoshenshan Hospital) in Wuhan, China. That hospital has been disbanded and all the documents has been sealed, so we cannot provide the copy of the ethics committee approval.

\section{Consent for publication}

Not applicable.

\section{Availability of data and materials}

All data generated or analysed during this study are included in this published article. 


\section{Competing interests}

The authors declare that they have no competing interests.

\section{Funding}

This work was supported by the [National Social Science Fund of China (Key Projects)] under Grant [number 17AGL024].

\section{Authors' contributions}

Conception and design of the research: $\mathrm{ZW}, \mathrm{XY}$; acquisition of data: $\mathrm{MM}, \mathrm{YH}$; analysis and interpretation of data: $X Y, J N$; statistical analysis: $Z W$; drafting the manuscript: $Z W, X Y$; revision of manuscript for important intellectual content: JN, XX.

\section{Acknowledgements}

None.

\section{References}

1. Simonovich VA, Burgos Pratx LD, Scibona P, Beruto MV, Vallone MG, Vázquez Cet al. A Randomized Trial of Convalescent Plasma in Covid-19 Severe Pneumonia. N Engl J Med 2021; 384(7):619-629.

2. Mazurskaya PZ. Organization of receptive fields in the forebrain of Emys orbicularis. Neurosci Behav Physiol 1973; 6(4):311-318.

3. Mupapa K, Massamba M, Kibadi K, Kuvula K, Bwaka A, Kipasa Met al. Treatment of Ebola hemorrhagic fever with blood transfusions from convalescent patients. International Scientific and Technical Committee. J Infect Dis 1999; 179 Suppl 1:S18-23.

4. Chen L, Xiong J, Bao L, Shi Y. Convalescent plasma as a potential therapy for COVID-19. Lancet Infect Dis 2020; 20(4):398-400.

5. Kraft CS, Hewlett AL, Koepsell S, Winkler AM, Kratochvil CJ, Larson Let al. The Use of TKM-100802 and Convalescent Plasma in 2 Patients With Ebola Virus Disease in the United States. Clin Infect Dis 2015; 61(4):496-502.

6. van Griensven J, Edwards T, de Lamballerie X, Semple MG, Gallian P, Baize Set al. Evaluation of Convalescent Plasma for Ebola Virus Disease in Guinea. N Engl J Med 2016; 374(1):33-42.

7. Zhou B, Zhong N, Guan Y. Treatment with convalescent plasma for influenza A (H5N1) infection. N Engl J Med 2007; 357(14):1450-1451. 
8. Hung IF, To KK, Lee CK, Lee KL, Chan K, Yan WWet al. Convalescent plasma treatment reduced mortality in patients with severe pandemic influenza A (H1N1) 2009 virus infection. Clin Infect Dis 2011; 52(4):447-456.

9. Cheng Y, Wong R, Soo YO, Wong WS, Lee CK, Ng MHet al. Use of convalescent plasma therapy in SARS patients in Hong Kong. Eur J Clin Microbiol Infect Dis 2005; 24(1):44-46.

10. Mair-Jenkins J, Saavedra-Campos M, Baillie JK, Cleary P, Khaw FM, Lim WSet al. The effectiveness of convalescent plasma and hyperimmune immunoglobulin for the treatment of severe acute respiratory infections of viral etiology: a systematic review and exploratory meta-analysis. J Infect Dis 2015; 211(1):80-90.

11. Zhao JY YJ, Qu JM. Diagnosis and Treatment Protocol for Novel Coronavirus Pneumonia (Trial Version 7). Chin Med J (Engl) 2020; 133(9):1087-1095.

12. Dong L, Hu S, Gao J. Discovering drugs to treat coronavirus disease 2019 (COVID-19). Drug Discov Ther 2020; 14(1):58-60.

13. Sallard E, Lescure FX, Yazdanpanah Y, Mentre F, Peiffer-Smadja N. Type 1 interferons as a potential treatment against COVID-19. Antiviral Res 2020; 178:104791.

14. Naydenova K, Muir KW, Wu LF, Zhang Z, Coscia F, Peet MJ et al. Structure of the SARS-CoV-2 RNAdependent RNA polymerase in the presence of favipiravir-RTP. Proc Natl Acad Sci U S A 2021; 118(7):2021946118.

15. Cai Q, Yang M, Liu D, Chen J, Shu D, Xia Jet al. Experimental Treatment with Favipiravir for COVID-19: An Open-Label Control Study. Engineering (Beijing) 2020.

16. Arabi Y, Balkhy H, Hajeer AH, Bouchama A, Hayden FG, Al-Omari Aet al. Feasibility, safety, clinical, and laboratory effects of convalescent plasma therapy for patients with Middle East respiratory syndrome coronavirus infection: a study protocol. Springerplus 2015; 4:709.

17. Duan K, Liu B, Li C, Zhang H, Yu T, Qu Jet al. Effectiveness of convalescent plasma therapy in severe COVID-19 patients. Proc Natl Acad Sci U S A 2020; 117(17):9490-9496.

18. Shen C, Wang Z, Zhao F, Yang Y, Li J, Yuan Jet al. Treatment of 5 Critically III Patients With COVID-19 With Convalescent Plasma. JAMA 2020.

19. Chen N, Zhou M, Dong X, Qu J, Gong F, Han Yet al. Epidemiological and clinical characteristics of 99 cases of 2019 novel coronavirus pneumonia in Wuhan, China: a descriptive study. Lancet 2020; 395(10223):507-513.

20. Huang C, Wang Y, Li X, Ren L, Zhao J, Hu Yet al. Clinical features of patients infected with 2019 novel coronavirus in Wuhan, China. Lancet 2020; 395(10223):497-506. 


\section{Tables}

Table 1 Comparison of laboratory test results before and after plasma transfusion

\begin{tabular}{lllll} 
& $\begin{array}{l}\text { White blood cell count } \\
\left(\times 10^{9} / \mathrm{L}\right)\end{array}$ & $\begin{array}{l}\text { Lymphocyte count } \\
\left(\times 10^{9} / \mathrm{L}\right)\end{array}$ & $\begin{array}{l}\text { C reaction } \\
(\mathrm{mg} / \mathrm{L})\end{array}$ & $\begin{array}{l}\mathrm{IL}-6 \\
(\mathrm{ng} / \mathrm{L})\end{array}$ \\
\hline Before transfusion & $7.76 \pm 2.88$ & $25.70 \pm 9.25$ & $11.14 \pm 12.79$ & $25.04 \pm 36.70$ \\
\hline After transfusion & $5.37 \pm 1.62$ & $37.48 \pm 10.62$ & $1.96 \pm 1.72$ & $9.23 \pm 12.56$ \\
\hline P value & 0.002 & 0.001 & 0.004 & 0.074
\end{tabular}

Figures

A

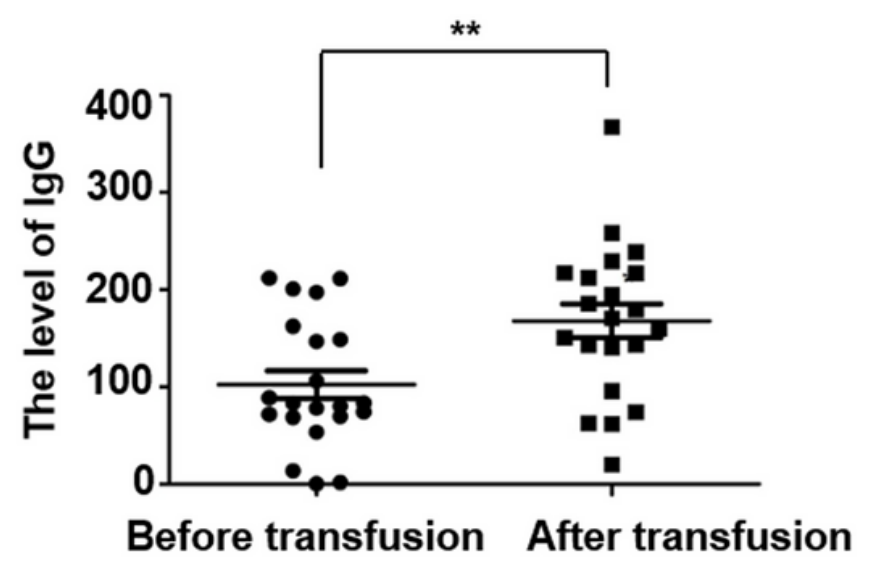

B

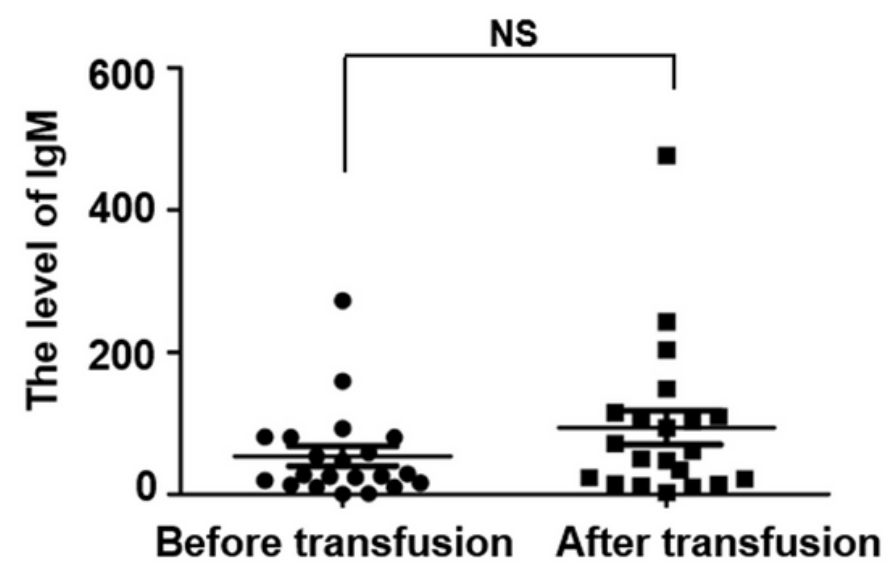

Figure 1

IgG and IgM levels. Before and after convalescent plasma transfusion, the levels of SARS-CoV-2 IgG (A) and $\lg M(B)$ in serum were detected by Elisa.

\section{Supplementary Files}

This is a list of supplementary files associated with this preprint. Click to download.

- Supplementarytables.doc 